\title{
Teachers' Conceptions of Teaching Physical Science in the Medium of English: Towards Additive Bilingualism?
}

\author{
Hamza Omari Mokiwa \\ Department of Science \& Technology Education, \\ College of Education, University of South Africa \\ Email:mokiwho@unisa.ac.za
}

\section{Doi:10.5901/mjss.2014.v5n2p79}

\section{Abstract}

In South Africa, linguistic diversity is high that policy makers and teachers are being faced with complex issues regarding appropriate ways of teaching a multilingual school population. Majority of teachers and learners come from a language background other than English, yet the language of teaching and learning in most schools is English. This paper reports on a research project which sought to explore the conceptions of English additional language (EAL) teachers about their teaching of Physical science in the medium of English. In this case study the data were collected from semi-structured interviews and lesson observations of four experienced EAL teachers in the KwaZulu-Natal Province of South Africa. Analysis of results showed that a majority of teachers prefer to code-switch, using of both English as well as mother tongue in their classrooms. Whilst there are many factors that influence this code-switching, teachers might use this to ease the problems of understanding on the side of the learners. On the other, teachers challenged by the complexities of second language teaching might prefer to use the children's mother tongue. Other dynamics include teachers who do not possess the required social and cultural capital linked to the second language. The conclusions found that apprehensive with the thought of examinations they tend to teach in a language they think their learners would understand better. These findings are significant because they contributes to a dynamic notion of additive bilingualism and that more work is required in teachers' pre-service and in-service training so as to enable them promote multilingualism as enshrined in the South African constitution.

Keywords: additive bilingualism, conceptions, physical science, language policy, scientific knowledge

\section{Introduction}

In South Africa, English dominate corridors of classrooms as the language of learning and teaching (LoLT) inspite that in historically black African (public) schools neither the teacher nor the learners have English as their main language. Although language diversity within the context of South Africa is supported, it may be argued, by the most progressive constitutional language provisions on the African continent (Bamgbose, 2003), questions about the LoLT are still unresolved. One of several reasons is that the right to choose the LoLT is still vested in the individuals. Learners, through school governing bodies (SGBs) have the right to choose the LoLT for their school, despite the obligation on the educational system to promote multilingualism as enshrined in the South African constitution. As well, the language in education policy (LiEP) of 1997 endorses dual medium education for which two or more languages will be perceived and used as LoLT by all learners (DoE, 1997); the focus being on additive bilingualism and development of all eleven (11) official languages. Of these official languages, English and Afrikaans were official languages during the apartheid dispensation. The other official languages are black African languages, sometimes referred to as indigenous languages: IsiZulu, IsiXhosa, IsiNdebele, Xitsonga, Tshivenda, SeSotho, Setswana, Sepedi and siSwati. Schools as constant language consumers should be custodians of this language policy. According to LiEP, not only can South African schools choose the language medium of teaching and learning, but there is a policy environment supportive of the use of languages other than the school's favoured language of learning and teaching (Setati, Chitera \& Essien, 2009). Therefore, code-switching is a common practice in many public schools where the majority of the learners are black Africans. The socio-linguistic survey of post-apartheid South Africa commissioned by Pan-South African Language Board (PanSALB) revealed that the comprehension of English seldom exceeds 30\% among speakers of African languages (PanSALB, 2000). PanSALB is a body established by government to create conditions to develop and promote equal use and engagement of all the official South African languages. It seeks to promote an awareness of multilingualism as a national resource.

EAL teachers in the study heed to the learners' language needs specifically for conceptual development. Second 
language (L2) learners face a number of dilemmas as documented by research. The L2 face the challenge of having to learn the language whilst they also try to master the content. Subjects like Mathematics, Biology and Physical Science can present specific challenges to learners whose first language is other than English. This article reports on the findings of teachers' conceptions of teaching Physical Science in the medium of English from four KwaZulu-Natal secondary schools. The following research questions guided the study:

- How do Physical Science teachers select their language of teaching outside the policy mandates?

- What challenges do they experience in balancing English proficiency and content mastering in the learners?

\section{Literature Review}

Conceptions of teaching is a research construct used by educational researchers which generally means the study of teachers' views or ideas about teaching (Clark \& Yinger, 1977). Conceptions of teaching Physical Science in the medium of English are regarded here as the teachers' views and ideas of the processes as well as how learners' acquire them. The value of investigating teachers' conceptions in relation to their instructional practice is strongly supported in the literature. Brown (2003) provides a compelling argument; that all pedagogical acts "are affected by the conceptions teachers have about the act of teaching, the process and purpose of assessment, and the nature of learning"(p.1). In some cases these conceptions may take preference over views and beliefs specific to Science teaching and may act as barriers to any change in pedagogical practices unless these conceptions are acknowledged, challenged and eventually changed (Richards \& Killen, 1993). Ayon (2012) points out that a number of factors will always affect the teachers' conceptions of teaching Science in L2.

The teachers' prior language learning experiences as pupils and experiences in teacher education are major influences on the teachers' conceptions. These conceptions or beliefs affect the teaching approach as well as the teachers' professional development. Canbay and Berecen (2012) also concur that the teachers' conceptions shape their instructional decisions in the classroom. They further posits that "what teachers do in their classrooms is oriented by their conception of teaching which are derived from their beliefs including a teacher's prior experiences, school practices, and a teacher's individual personality" (p.71). Teachers form conceptions consciously and these guide their teaching throughout their careers. These personal constructs can also serve as lenses of understanding classroom events (Jones \& Carter, 2007; Zuljan, 2007). Furthermore, Nespor (1987) adds that to understand teachers' perspectives we have to understand the beliefs with which they define their work.

The concept, English Additional Language (EAL) is used to describe individuals whose main language is any language other than English. To Rollnick (2000), EAL Science teachers can be grouped into two broad categories. Category 1 is made up those who are citizens in a given country and from a language background other than English, but who teach Science in English. While Category 2 comprises of those who have come to a given country having received part or all of their schooling in a language other than English, but teach Science in English. The majority of the teachers in South Africa fall under Category 1. This is because majority of South Africans speak one or more indigenous African language as their mother tongue (Statistics South Africa, 2012). This study focuses only on Category 1 teachers. Several authors in South Africa (see for example, Alant \& Malcolm, 2004; Mokiwa \& Msila 2013; Mokiwa, 2007; Muwanga-Zake, 2004; Qhobela, Rollnick \& Stanton, 2003; Rollnick, 2000) provide much information about issues and perspectives on L2 teaching and learning of Science. A number of these studies have explored language issues for learners in Science classrooms. Despite the heated discussions and debates concerning the importance of the use of mother-tongue in the context of learning and teaching, English continues to dominate the corridors of education in South Africa and in most African countries (Mgqwashu, 2004). This trend continues even though nearly $80 \%$ of the South African population uses at least an African language as their home language (Statistics South Africa, 2012).

Bertram (2006) who studied teachers' ability to read English, found that one third of a sample of teachers in a postgraduate programme at the University of KwaZulu-Natal 'struggled to read to learn' (p. 5-18). Naidoo (2003) noted deficient language skills among the teachers that impact their ability to express themselves in writing, particularly in their answers to free response items. Most teachers already experience a great deal of discomfort with regard to the manner in which they teach Science. This sense of discomfort is further compounded by the fact that in many black African schools, the language of learning and teaching used is not a mother tongue for both learners and teachers. Yet the paradox in this is that many black South African parents prefer English as the language of learning and teaching because they perceive it as a language that opens up more opportunities (Bloch, Stein \& Prinsloo, 2001). Another reason for not choosing indigenous languages as language of learning and teaching is that they lack the precise grammatical structures such as logical connectiveness and locative constructions needed in the sciences (Rutherford \& Nkopodi, 1990). 


\title{
2.1 Additive bilingualism
}

Cummins (2000) defines the term additive bilingualism as the form of bilingualism that occurs when learners add the L2 to their intellect while continuing to develop their first language (L1) conceptually and academically. To Heugh (1999), additive bilingualism is the bilingualism associated with a well-developed proficiency in two languages and with positive cognitive outcomes. Heugh further assert that the term is applied to a situation where the speakers of any language are introduced to L2 (or even languages) in addition to the continued educational use of the L1 as LoLT. The introduction of L2 is not to replace L1, but rather to compliment it. Jegede (1995) posits that communication in a language requires not only a language structure, but also the propagation of a culture and values embedded in that language or bordercrossing. This would mean that black South African learners assume a foreign culture as they learn and communicate Science in English.

In their study, Skutnabb-Kangas and Toukomaa (1977) found that L2 students suffer academic difficulties when their home language is replaced by the L2. From this we can argue that cognitive gains are only made when bilingualism is additive i.e. when L2 is learnt while students' home language is maintained. Surprisingly many Black South African parents fear that their children would lack socio-economic access and mobility if they are to be taught in their home languages (De Klerk, 1995). They prefer English as the LoLT. In the literature we find copious societal and career benefits of science, yet many learners in multilingual South Africa are not motivated to study sciences. The big question here is what strategies are appropriate for use in these multilingual science classrooms? Embedded in this question are issues about language and learning and also about motivating learners' interest in sciences.

\subsection{Theoretical underpinnings}

This study is largely informed by an understanding of language as a transparent resource (Lave \& Wenger, 1991). According to them, access to a practice relates to the dual visibility and invisibility of its resources, in that:

\begin{abstract}
Invisibility is in the form of unproblematic interpretation and integration into activity, and visibility is in the form of extended access to information. This is not a dichotomous distinction, since these two crucial characteristics are in a complex interplay, their relation being one of both conflict and synergy. (p. 103).
\end{abstract}

For the language in the classroom to be useful it must be both visible and invisible. Language must be visible so that it is clearly understood by all; and invisible in that when engaging in science discussion and written texts, this use of language should not divert ones' attention instead, facilitate their learning.

This idea is similar to the use of technology in science teaching and learning. The technology needs to be visible so that the learners can notice and use it. However, it also needs to be invisible so that the learners' attention is focused on the science problem that they are trying to solve. Like technology, language needs to be a transparent resource. As Lave and Wenger (1991) argue the idea of the visibility and invisibility of a resource is not a dichotomous distinction, it is not about whether to focus on language or science; it is about recognizing that the two are constantly entwined. I found Lave and Wenger's concept of transparency useful in exploring teachers' conceptions of teaching science in the medium of English. EAL teachers in the study are characterized by complex multiple teaching demands ranging from learners' limited proficiency in English to the challenge of ensuring learners' epistemological access.

\section{Methodology}

This study adopted a qualitative methodology approach using an intrinsic case study design that examines EAL teacher's conceptions of teaching Physical science in the medium of English. An intrinsic case study was deemed appropriate since I wanted to gain a better understanding of this particular case (Yin, 2009) and it used a small number of participants (Creswell, 2013).

\subsection{The participants}

A purposive and convenience sample of four teachers from KwaZulu-Natal Province was used. Conceptions of teaching Physical Science in the medium of English, was informed by data from the sample, it can be thought as a collective case study (Stake, 2006). The rationale for using a multiple participant design was to inform the case by producing potentially contrasting results for predicable reasons (Yin, 2009). All the participants teach Physical Science at the Further 
Education and Training (FET) Band. Within the context of South African education the FET Band includes grades 10 to 12. It also includes career-oriented education and training offered in other Further Education and Training institutions technical colleges, community colleges and private colleges. A large number of their learners come from poor social economic backgrounds. Some learners come from either a child-headed family or from a single parent family. The main language in the area is IsiZulu, which is one of the 11 official languages in the country.

It is important to mention here that, although this study sample cannot be regarded as a precise representative of all the Physical Science teachers in KwaZulu-Natal Province; the findings may nevertheless be substantively applicable to other teachers in similar settings. Table 1 below shows the characteristics of the participants:

Table 1: Characteristics of the participants

\begin{tabular}{cccccc}
\hline Teacher & Gender & Academic qualification & Teaching experience in years & Grades taught & First language \\
\hline T1 & Male & B.Ed. Hon & 13 & $11 \& 12$ & IsiZulu \\
T2 & Male & B.Ed. Hon & 13 & $10 \& 11$ & SeTswana \\
T3 & Male & B.Ed. ${ }^{*}$ & 09 & $9 \& 11$ & IsiZulu \\
T4 & Male & B.Ed. ${ }^{*}$ & 11 & $10 \& 11$ & IsiZulu \\
\hline
\end{tabular}

* Bachelor of Education

${ }^{* *}$ Bachelor of Education Honours

\subsection{Data collection}

Three methods of collecting data were used, namely, individual interviews, lesson observations and focus group interviews. The choice to use multiple data collection methods has long been emphasised by researchers in science education (Schwartz \& Lederman, 2008) but more importantly, it is suitable in answering research questions in the study. The collection of data was carried out in three phases. Phase 1 comprised of individual interviews while phase 2 entailed the observation of lessons. The last phase i.e. phase 3 comprised of focus group interviews. This strategy afforded me an opportunity to review and analyse results from one phase and then tailor the phase that follows in order to make further clarifications and follow-up on significant responses (Corbin \& Strauss, 2008).

Data from phase 1 were audio-taped after consent was granted by the participants. Research ethics require researchers to ask for consent whenever their utterances are to be recorded. The duration of these interviews were between 45-60 minutes. The interviews were triangulated with lesson observations as well as focus group discussion among the four. Each participant was observed twice while teaching Physical science in a period of twelve months. The first interview was conducted during the first week and the second one just before the finalization of the study. For trustworthiness of data from interviews and group discussions transcript were taken back to the participants to verify if the transcriptions reflected their intended views. A few semantic changes were made to the satisfaction of the participants. In case of lesson observation the contextual features as suggested by Cohen and Manion (2000) regarding learning and teaching process in relation to language of learning and teaching was used by ticking items as they happen during lesson observations.

\subsection{Analysis of data}

The analysis of data was done thematically i.e. data from participants was subjected to open, axial and selective coding (De Vos et al., 2011). Open coding was done line by line, followed by axial coding where paragraphs were compared to give precision to a category. Lastly, core categories were selected during selective coding. The analysis was also done in three phases. The first phase involved, transcribing the audio-recorded data. Then the transcripts were read several times in order to get familiar with them. This was followed by coding the data. This being a case study of the conceptions of four EAL teachers, my emphasis was on the discussion and classification of their views rather than on the teachers themselves. In the second phase data from the lesson observations were grouped into categories. Lesson observations aimed at interrogating the EAL teachers' instructional practices. This approach was deemed appropriate as it serves as a way to validate and triangulate the interviews. In phase 3, the data from the focus group discussion was transcribed then coded using open coding. 


\section{Findings}

Results from phase 1 showed that explored what the EAL teachers make of the statement "proficiency in English language is a prerequisite to Science knowledge". Three out of the four participants agreed with the statement (T1 to T4 refers to teachers 1 to 4 ).

T1: I agree with this statement because there is a term here "proficiency" How do you expect an African child who started to learn English at his or her secondary level to be good at English? We are brought up in these disadvantaged communities and we learnt in these miserable schools where we had unqualified teachers, some of them didn't know English, so how can you expect learner to be proficient in English in their schools?

T2: I don't believe in that...the best thing is for the learners to understand. Some teachers just teach learners terminologies not explaining the meanings.

T3: Yes; you need to know English in order to learn or teach Science ....We were made to believe that fluency in English means intelligence; and only intelligent students were allowed to do science. It was the system of education those days. That was the criteria so that on its own gave us recognition. It made us feel big in a small town.

T4: Yes it is, because learners will be able to understand questions in exams and have the language to answer what they have already conceptualized in their languages.

With regard to question 2, which sought to explore the teachers' preference in relation to English, three preferences were noted:

- The use of both IsiZulu and English in the teaching of Science;

- The use of IsiZulu only in the teaching of Science and;

- The use of English only in the teaching of Science.

The participants added:

T1: Perhaps if we can try to use both languages, English and the mother tongue in the teaching. At least there must be $70 \%$ mother tongue and $30 \%$ English if we want the learner to understand.

T2: My home is in the North West Province and I'm working in KwaZulu- Natal Province. Now that means each and every teaching is in English because here I cannot speak Isizulu. So I prefer English. I don't want to use the home language in teaching Science as it is going to make those learners not to be able to read and understand question papers. But using English language is going to make them get used to the language of exam papers, that's why I prefer English.

T3: I would love to teach Science in IsiZulu, because we spend most of the time trying to interpret what is in English and then back to IsiZulu, and for these learners if there was an IsiZulu Science book maybe things were going to be simpler, because even at home parents were going to be able to help their learners during their study time.

T4: I would prefer teaching Science in IsiZulu, reason being I believe that classroom science can only be useful to my learners if they are able to apply it in their lives. And they can only be able to apply it after they have already conceptualised it in their languages. It is easy if we start with let's say Isizulu, then, after understanding the aspects in Isizulu, we bring in English.

Results from lesson observations i.e. phase 2, formed the second set of data. Table 2 below provides a summary of all the contextual features as suggested by Cohen, Manion and Morrison (2011) of the learning and teaching process in relation to LoLT. The three main languages for the participants and their learners are English-E; IsiZulu- Z; SeTswana$\mathrm{T}$.

Table 2: Themes that guided lesson observations

\begin{tabular}{|c|c|c|c|c|c|c|c|c|c|c|c|c|}
\hline & \multicolumn{3}{|c|}{ T1 } & \multicolumn{3}{|c|}{ T2 } & \multicolumn{3}{|c|}{ T3 } & \multicolumn{3}{|c|}{ T4 } \\
\hline How is language used in the classroom in terms of: & E & $\mathbf{Z}$ & $T$ & E & $\mathbf{Z}$ & $\mathrm{T}$ & $\mathbf{E}$ & $\mathbf{Z}$ & $\mathrm{T}$ & $\mathbf{E}$ & $\mathbf{Z}$ & $T$ \\
\hline Concept development & & $x$ & & $\mathrm{x}$ & & & & $x$ & & & $x$ & \\
\hline Classroom-led group discussion & & $x$ & & $\mathrm{x}$ & & & $x$ & & & $x$ & $x$ & \\
\hline
\end{tabular}




\begin{tabular}{|l|c|c|c|c|c|c|c|c|c|c|c|c|}
\hline Teacher-learner discussion & & $\mathrm{x}$ & & $\mathrm{x}$ & & $\mathrm{x}$ & & & & $\mathrm{x}$ & \\
\hline Learner-teacher discussion & $\mathrm{x}$ & $\mathrm{x}$ & & $\mathrm{x}$ & & $\mathrm{x}$ & $\mathrm{x}$ & & $\mathrm{x}$ & $\mathrm{x}$ & \\
\hline Classroom regulation of learner activity & $\mathrm{x}$ & $\mathrm{x}$ & & $\mathrm{x}$ & & & $\mathrm{x}$ & & & $\mathrm{x}$ & $\mathrm{x}$ & \\
\hline Classroom regulation of Discipline and management & $\mathrm{x}$ & & & $\mathrm{x}$ & & & $\mathrm{x}$ & & & $\mathrm{x}$ & & \\
\hline $\begin{array}{l}\text { Linking learners' experiences and interests to the world outside } \\
\text { school, that is, in- and -out of school experiences }\end{array}$ & $\mathrm{x}$ & $\mathrm{x}$ & $\mathrm{x}$ & & & $\mathrm{x}$ & & & $\mathrm{x}$ & $\mathrm{x}$ & \\
\hline Percentages & 40 & 60 & 0 & 100 & 0 & 0 & 71 & 29 & 0 & 50 & 50 & 0 \\
\hline
\end{tabular}

The above findings indicate that T1 and T4 in the study demonstrated a one-to-one relationship between their conceptions and the use of English in the teaching of Science. This was evident in the three themes; learner-teacher discussion, classroom regulation of learner activity and linking learners' experiences and interests to the world outside school. This showed consistency between participants' espoused theories and instructional practice.

There was also evidence of consistency in the Concept Development theme for participants. T2 showed a one-toone relationship between his conceptions and the use of English in the teaching of Science. He uses only English throughout his teaching. What is exciting here is that all participants in the study use English for classroom regulation of discipline and management. In general, the findings from the observed lessons revealed that the EAL teachers' espoused theories informed their instructional practice to a great extent. There is no tension or dilemma between what the teachers say or profess to believe and their classroom practices, namely, the use of English in teaching Science.

Findings from phase 3 : Contrary to the findings of the individual interviews which pointed to three preferences, the analysis of the focus group interview reflected two preferences, namely:

- The use of both mother tongue and English is seen as a vehicle for accessing scientific knowledge; and

- The use of English only is seen as a vehicle for accessing scientific knowledge.

In general, analysis of data collected findings from the interview schedule and focus group interview allude to the following. EAL teachers preferred the use of:

- Both English and mother tongue as vehicles for accessing scientific knowledge; and

- English only as the vehicle for accessing scientific knowledge.

However, these preferences suggest a dichotomy of socio-economic and examination issues. Social issues include their disadvantaged milieu characterised by under-qualified teachers, while examination issues include English as a language of examination. Furthermore, it was observed that the teachers' conceptions depended on what they foregrounded. When understanding is foregrounded, teachers tend to opt for IsiZulu together with English as the medium. When examinations are foregrounded, however, English is seen as the suitable medium for teaching. Therefore, it can be argued that the teachers in the study perceive understanding in Physical Science to be achievable through other means or languages other than English. However, they draw a clear distinction between teaching for understanding and teaching for examination.

\section{Discussion}

Discourses regarding diversity, bilingualism and multilingualism and their implications for the education constitute the social context for the study. EAL teachers in the study, who all falls under category 1, are truly caught in the crossfire of these discourses. Findings from the case interviews indicated that some teachers prefer the use of:

- Both English and mother tongue as vehicles for accessing scientific knowledge; and

- English only as the vehicle for accessing scientific knowledge.

Discussion around these preferences, however, has two qualifiers, that issues of language acquisition or proficiency in English cannot be divorced from the socio-economic issues of learning Science and issues of English as a language of examination. Their conceptions play a major role in shaping their instructional practices i.e. what teachers foreground form the basis of their views and conceptions. For instance, when understanding is foregrounded, teachers tend to opt for both IsiZulu and English as the language of teaching and learning. When examinations are foregrounded, English is seen as the suitable medium for teaching. The findings of the study also provide support for the idea that Physical Science teachers in the similar contexts to those participants under study hold uncomplicated conceptions of teaching, at least when compared to Hewson \& Hewson's (1988) ideas about an appropriate conception of teaching Science.

Similar to the findings reported by Aguirre et al. (1990). Although the majority of EAL teachers emphasize a transmission approach to Physical Science teaching, they pay heed to linguistic challenges faced by learners and by 
themselves, hence opting for code-switching. I argue that this has been influenced by the current LiEP that gives authoritative powers to SGBs to determine their respective language of teaching policies while failing to recognize educators' inputs in the implementation of the language policy. This is what Cummins (2004) called a xenophobic discourse about linguistic diversity in that it limits the educational options that are seen reasonable for both, EAL teachers and L2 learners. Consequently, we find teaching styles with more emphasis on the mastery of abstract concepts and principles, and little connection with day-to-day lived experiences of learners (Kyle, 2006, Onwu \& Kyle, 2011). Yet, the National Curriculum Statements (NCS) and the recently launched Curriculum and Assessment Policy Statement (CAPS) put more emphasis on practical applications of scientific knowledge (DBE, 2011).

These findings are reasons for concern, especially when viewed against the notion of additive bilingualism. EAL in the study believe that learners need language empowerment that will enable them to meaningfully participate in the scientific culture. Their conceptions support the idea of pursuing language policy that is most supportive of general conceptual growth amongst learners.

\section{Conclusion and recommendations}

In South Africa, an effort has been made to allow people to express themselves using any of the eleven official languages and code switching is a common practice in South African classrooms. The findings from this study recommend the following:

- There is a need for all education stake holders to address the need for typical additive bilingualism practices which will empower learners from diverse linguistic society.

- In terms of promoting multilingualism in South African classrooms, some of the observed teachers' conceptions seem to be in line with national language policy. The study recommends EAL teachers to explore a variety of conceptions of teaching and learning of Science.

- Policy needs to spell it out well as to how strategies such as code-switching can be used in a pedagogically sound way in L2 classrooms. This is an urgent matter for as long as language is a barrier in some classrooms, there will be few future scientists who are L2 or third language speakers of the language of instruction.

- More work is required in teachers' pre-service and in-service training so as to enable them promote multilingualism as enshrined in the South African constitution.

\section{References}

Aguirre, J. M., Haggerty, S. M. \& Linder, C. J. (1990). Student-teachers' conceptions of science, teaching and learning: A case study in pre-service teacher education. International Journal of Science Education, 12: 381-390.

Alant, B., \& Malcolm, C. (2004). Finding direction when the ground is moving: Science education research in South Africa. Studies in Science Education, 40, 49-104.

Bamgbose, A. (2003). The future of Multilingualism in South Africa: From policy to practice. Paper read at Language Conference of the Department of Arts and Culture, Kopanong, Johannesburg, 12-13 June, 2002.

Bertram. C. (2006). Exploring teachers' reading competences: a South African case study. Open Learning 21(1), 5-18.

Bloch, C; Stein, P., \& Prinsloo, M. (2001). Progress report on the Children's Early Literacy Learning (CELL) research project in South Africa. Journal of Early Childhood Literacy, 1(1):121 \& 122.

Brown, G. (2003). Teachers' instructional conceptions: Assessments' relationship to learning, teaching, curriculum and teacher efficacy. Paper presented at the joint Conference of the Australian and New Zealand Association $\mathrm{s} f$ or Research in Education (AARE/NZARE), Auckland, 28 Nov.-3 Dec.

Canbay, O. \& Beceren, S. (2012). Conceptions of teaching held by the instructors in English language teaching departments. Turkish Online Journal of Qualitative Inquiry, 3(3): 71-81.

Clark, C. \& Yinger, R. J. (1977). Research on teacher thinking. Curriculum Inquiry 7(4), 279- 304

Cohen, L., Manion, L., \& Morrison, K. (2011). Research methods in education (7 $7^{\text {th }}$ ed.). London. Routledge Falmer.

Corbin, J., \& Strauss, A. (2008). Basics of qualitative research. Los Angeles: Sage.

Creswell, J.W. (2013). Qualitative inquiry and research design: Choosing among the five approaches (3rd ed.). Los Angeles: Sage.

Cummins, J. (2004). Language, power and pedagogy: Bilingual children in the crossfire. Cleverdon: Cambrian.

De Klerk, G. (1995). Slaves of English. In Heugh, K., Siegruhn, A. and Pluddeman P. (Ed.), Multilingual education for South Africa (pp. 8-14). Johannesburg: Heineman.

Department of education. (1997). Language-in-education policy. Pretoria: Department of Education.

Department of Basic Education. (2011). Curriculum and Assessment Policy Statement CAPS: Physical Sciences. Pretoria: Government Printers.

De Vos, A. S., Strydom, H., Fouche, C. B., \& Delport, C. S. (2011). Research at grass roots. (4th Ed.). Pretoria: Van Schaik. 
Heugh, K. (1999). Languages, development and reconstructing in education in South Africa. International Journal of Educational Development, 19, 301-313.

Hewson. P.W. \& Hewson. M. G. (1988). An appropriate conception of teaching Science: A view from studies of Science learning Science Education, 72: 597-614.

Jegede, O. (1995). Collateral learning and the eco-cultural paradigm in science and mathematics in Africa. International Journal of Science Education 25, 97-137.

Jones, M. G. \& Carter, G. (2007). Science teacher attitudes and beliefs. In S. K. Abell \& N.G. Lederman (Eds.), Handbook of research on science education (pp. 1067- 1104). Mahwah, New Jersey: Lawrence Erlbaum Associates.

Keys, C.W. \& Bryan, L.A. (2001). Co-constructing inquiry-base science with teachers: Essential research for lasting reform. Journal of Research in Science Teaching, 38, 631-645.

Kyle, W. C., Jr., (2006). The Road from Rio to Johannesburg: Where the footpaths to/ from Science Education? International Journal of Science and Mathematics Education, 4, 1-18.

Lave, J., \& Wenger, E. (1991). Situated learning: Legitimate peripheral participation. Cambridge, UK: Cambridge University Press.

Marton, F., \& Booth, S. (1997). Learning and awareness. Mahwah, NJ: Erlbaum.

Mokiwa HO (2007). Teachers' conceptions of teaching science in the medium of English: a case study of four English as additional language (EAL) teachers in KwaZulu-Natal. Unpublished Master of Education Dissertation. Durban: University of KwaZulu-Natal.

Mokiwa, H.O., \& Msila, V. (2013). Teachers' conceptions of teaching science in the medium of English: a case study. The International Journal of Educational Science, 5(1), 55-62.

Mgqwashu EM (2004). The South African Language Policy-in- Education: realistic or ideological import? Proceedings of the 2004 Annual Conference Joint AUETSA, SAVAL, and SAACLALS, University of KwaZulu-Natal, Durban. Retrieved on September 16, 2006 from http://www.uwc.ac.za/arts/auetsa/emmanuelMgqwashu.htm

Muwanga-Zake, J.W.F. (2004). What kind of science do educators present to learners in South African classes? Centre for the Advancement of Science and mathematics Education (CASME), University of KwaZulu-Natal, South Africa.

Naidoo, J.T. (2003). The impact of a Life Science module on teachers' scientific literacy. Unpublished MEd Dissertation. Pietermaritzburg: University of Natal.

Nespor, J. (1987). The role of beliefs in the practice of teaching. Journal of Curriculum Studies 19, 317-328.

Onwu, G. O.M, \& Kyle, W. C., Jr., (2011). Increasing the socio-cultural relevance of science education for sustainable development. African Journal of Research in MST Education, 15 (3), 2-26.

PanSALB. (2000). Summary of the findings of a sociolinguistic survey on language use and language interaction in South Africa. Pretoria: PanSALB.

Qhobela, M., Rollnick, M., \& Stanton, M. (2003). Helping students talk the language of Science. In Proceedings of the 11th Annual SAARMSTE Conference, (ed.), B. Putsoa, M. Dlamini, B. Dlamini, and V. Kelly, 459-63. Mbabane: University of Swaziland.

Richards C, Killen R 1993. Problems of beginning teachers: Perceptions of pre-service music teachers. Research Studies in Music Education 1, 40-51.

Rollnick, M. (1998). The influence of language on second language teaching and learning of science. In W.Cobern (Ed.), Socio-cultural perspectives on science education: An international dialogue(121-131). Dordretch: Kluwer.

Rollnick, M.(2000). Current issues and perspectives of the second language learning of science, Studies in Science Education, 35, 93122.

Rutherford, M. \& Nkopodi, N. (1990). A comparison of the recognition of some science concept Definitions in English and North Sotho for second language speakers. International Journal of Science Education 12, 443-456.

Schwartz, R. \& Lederman, N. (2008). What scientists say: scientists' views of nature of science and relation to science context. International Journal of Science Education, 30(6), 727-771.

Setati, M., Chitera, N. \& Essien, A. (2009). Research on multilingualism in mathematics Education in South Africa: 2000-2007. African Journal of Research in MST Education, Special Issue 2009, 65-80.

Skutnabb-Kangas, T. \& Toukomaa, D. (1977). The colonial legacy and language planning in sub-Saharan Africa. Clevedon: Multilingual matters.

Stake, R. E. (2006). The art of case study research. London. Sage.Statistics South Africa. (2012). Census 2011. [Online] Available: http://www.statssa.gov.za/Publications/P03014/P030142011.pdf (October 20, 2013)

Yin, R.K. (2009). Case study research: Thousand Oaks, CA: Sage.

Zuljan. M. V. (2007). Students' conceptions of knowledge, the role of the teacher and learner as important factors in a didactic school reform. Journal of Educational Studies, 33(1), 29-40. 